\title{
CIDADES-JARDINS VERSUS CONDOMÍNIOS FECHADOS DE LUXO: AMEAÇA AO DIREITO À CIDADE FRENTE A APROPRIAÇÃO DA NATUREZA NO MEIO URBANO
}

\author{
Juliana Campos de Oliveira* \\ Rafaela Campos de Oliveira**
}

\begin{abstract}
Resumo
Pretende-se descrever Cidade-Jardim de Ebenezer Howard, influência no Brasil, enfocando sua deturpação nos Condomínios Fechados Luxo em Salvador, Bahia, utilizando método pesquisa bibliográfica, fontes primárias e secundárias. Na Inglaterra, século $\mathrm{XX}$, modelo Cidade-Jardim howardiano sugeria ambiente urbano aprazível, salubre para todos. Posteriormente, houve tentativas de reprodução desta proposta mundialmente, inclusive no Brasil. Contudo, desvirtuavam-se princípios Howardianos. Atualmente, em Salvador, presencia-se implantação dos condomínios fechados de luxo, segregacionistas, inspirados nas cidades-jardins inglesas, mas, reproduzindo desigualdades socioeconômicas, perpetuando não-democratização do espaço urbano, ferindo Legislação AmbientalUrbanística Brasileiros, opondo-se ao Direito à Cidade e dispositivos Constitucionais garantidores da Função Social da Cidade.
\end{abstract}

Palavras-chave: Cidade-Jardim de Howard; Condomínios Fechados de Luxo; Direito à Cidade; Função Social; Apropriação da Natureza.

\section{GARDEN CITIES VERSUS LUXURY GATED COMMUNITIES: THE THREAT TO THE RIGHT TO THE CITY BY THE APPROPRIATION OF NATURE IN THE URBAN ENVIRONMENT}

\begin{abstract}
This paper intends to describe Ebenezer Howard's Garden Cities and it influence in Salvador, Bahia,Brazil. At this paper it was used Primary and Secondary source as bibliographic research methodology. The Howard Garden-City model suggested a pleasant urban environment, wholesome for everyone. That model was reproduced worldwide. However, Howardian principles were distorted. Currently, in Salvador, there is the Luxury Gated Communities, inspired by Howard. Actually, they are reproducing socioeconomic inequalities and they are segregationist.Gated Communities are perpetuating the non-
\end{abstract}

\footnotetext{
*Doutoranda em Arquitetura e Urbanismo pelo Programa de Pós-Graduação em Arquitetura e Urbanismo da Universidade Federal da Bahia (PPGAU/UFBA); Mestre em Direito Público pelo Programa de PósGraduação em Direito da Universidade Federal da Bahia (PPGD/UFBA); Especialista em Direito do Estado pela Fundação Faculdade de Direito da Universidade Federal da Bahia (FFD/UFBA); Graduada em Direito pela Universidade Estadual da Paraíba (UEPB). E-mail: juli.camposo@ gmail.com

${ }^{* *}$ Doutoranda em Arquitetura e Urbanismo pelo Programa de Pós-Graduação em Arquitetura e Urbanismo da Universidade Federal da Bahia (PPGAU/UFBA); Mestre em Arquitetura e Urbanismo pelo Programa de PósGraduação em Arquitetura e Urbanismo da Universidade Federal da Bahia (PPGAU/UFBA); Especialista em Direito Ambiental pela Fundação Faculdade de Direito da Universidade Federal da Bahia (FFD/UFBA); Graduada em Direito pela Universidade Estadual da Paraíba (UEPB).

E-mail: rafinhabmcampos@yahoo.com.br
} 
democratization of urban space. They oppose the Brazilian Environmental-Urbanistic Law, the Major Law. The City's Social Function are disrespected by Brazilian's model also.

Keywords: Howard's Garden Cities; Luxury Gated Communities; Right to the City; City's Social Function; Appropriation of Nature.

\section{Introdução}

$\mathrm{Na}$ Inglaterra, por volta do início do século XX, em meio ao contexto de crescimento caótico das cidades decorrente, sobretudo, da Revolução Industrial, Ebenezer Howard elaborou modelo que denominou Cidade-Jardim, a partir do qual, indicava a inserção da natureza nas cidades, como forma de, entre outros fatores, obter ambiente urbano mais aprazível e salubre para todos.

Naquela ocasião, buscava-se, solucionar questões epidêmicas oriundas da explosão populacional ocorrida nas cidades e consequente crescimento urbano desordenado.

O papel dos recursos do meio ambiente natural enquanto fontes capazes de oferecer maior salubridade, quando agregados ao cotidiano da urbe, era reconhecido. Diferentemente do que se propaga atualmente, em tempos de pandemia, o convívio homem-natureza era visto como plenamente salutar e desconheciam-se os perigos que pudessem advir desta interação. A concepção era bucólica.

Com o passar dos anos, houve tentativas de reprodução das propostas de Howard em todo o mundo, inclusive no Brasil. Contudo, tendia-se a realizar esboços que, na prática, desvirtuavam-se dos princípios por ele defendidos. Isto porque se projetavam bairros repletos de áreas verdes, todavia, bairros elitizados, onde as habitações eram vendidas a altos valores, sendo proibida a presença de indústria e comércio.

Atualmente, no Brasil, além de tais modelos de bairros, presencia-se, com frequência, a implantação dos denominados condomínios fechados de luxo, espaços exclusivistas e segregacionistas que, de modo deturpado, difundem a ideia de reconfiguração das cidades-jardins inglesas, agregando, porém, caráteres que são discordantes da legislação urbanística e ambiental vigente nas cidades.

O descompasso entre o ideal de Howard e os atuais condomínios fechados de luxo estilo "jardins" brasileiros reside, sobretudo, no fato de que, contrariamente ao que se propõem tais empreendimentos, Howard defendia a existência de cidades cooperativas, que conciliassem indústria, comércio, habitação e natureza, aspirando a uma cidade que oferecesse, auto-suficiência, de forma igualitária, habitação de qualidade e sobrevivência 
saudável a todos os seus integrantes, em especial, à classe operária, maior afetada pelas consequencias do crescimento urbano caótico. Por outro viés, os condomínios fechados de luxo, atuais, ao elitizar seu público-alvo, ferem princípios e leis, tornam o bem ambiental exclusivo, ao restringir acesso à praias, parques entre outros, afetando o Direito à Cidade, o Acesso à Natureza nas Cidades, o Direito de ir e vir, e, a Função Social das Cidades.

Assim sendo, o presente trabalho tem o objetivo de desconstruir a ideia de que os atuais condomínios fechados de luxo, no Brasil, que pretendem agregar habitação e convívio com a natureza, configuram modelos de cidades-jardins, visto que seus objetivos são díspares, ao segregar determinadas camadas da população do usofruto dos serviços ambientais e do direito amplo à cidade e, consequentemente, ao estabelecer conflitos com a Constituição Federal de 1988 e o Estatuto da Cidade.

Para tanto, pretende-se descrever o legítimo modelo de Cidade-Jardim, proposto por Ebenezer Howard, ressaltando o contexto histórico em que foi desenvolvido e a gradual deturpação dos seus escopos até a implantação dos atuais condomínios fechados de luxo no Brasil, realizando enfoque à cidade de Salvador, utilizando-se, para tanto, de pesquisa bibliográfica de fontes primárias e secundárias, que retratam os cenários nacional e local existentes anteriormente à atual pandemia, que tem assolado as cidades ao redor do mundo.

\section{O modelo proposto por Ebenezer Howard: As Cidades-Jardins}

\subsection{Contexto Histórico}

A ideia de cidade-jardim desenvolvida por Ebenezer Howard foi delineada em Londres, entre o final do século XIX e o início do século XX. De acordo com Dacio Ottoni, introdutor do livro "Cidades-Jardins de amanhã", desde o século XVIII, presenciou-se, na Inglaterra, a expansão da indústria têxtil, que angariava mão-de-obra a partir de crescente aglomerado de homens e mulheres sem-trabalho nas cidades, provenientes das grandes propriedades rurais, de onde foram expulsos em decorrência do incremento de novas técnicas e máquinas agrícolas, que modernizaram o campo e desempregaram massas de trabalhadores rurais (HOWARD, 2002).

Desde meados do século XVII, quando cessou o processo absolutista inglês, Londres passava a conviver com o crescimento do mercantilismo comercial e o 
desenvolvimento do liberalismo político, cujos reflexos mais marcantes para as cidades puderam ser observados a partir do século XVIII, no apogeu da Revolução Industrial.

Todos estes processos ensejaram o crescimento econômico da burguesia inglesa, que passou a alojar-se em Londres, em elegantes bairros residenciais, no entorno da cidade, repletos de praças arborizadas (IDEM). Ressalte-se que a afeição dos ingleses pelo ambiente campestre é aspecto marcante, historicamente inerente ao seu perfil, o que influenciou no desenvolvimento de modernos parques em Londres e na prática de esportes ligados à interação com a natureza.

Paralelamente, a Revolução Industrial gerou realidade oposta àquela vivenciada pela abastada burguesia inglesa. $\mathrm{O}$ acelerado aumento populacional nas cidades, a poluição do ar e dos cursos d'água, a falta de higiene, trouxeram como consequência graves epidemias e deterioração do ambiente urbano, cujos reflexos foram mais incisivos sobre a grande massa de operários provenientes do campo, que, sem emprego, habitavam precariamente a cidade.

Engels, ao descrever bairros operários de Manchester retratou a precária condição de vida da maioria da população inglesa:

\begin{abstract}
todas as grandes cidades possuem 'bairros de má reputação' onde se encontra a classe operária (...) é frequente a pobreza morar em vielas escondidas, muito perto do palácio dos ricos, mas, em geral, designamlhe um lugar a parte, onde, ao abrigo dos olhares das classes mais felizes, tem de se safar sozinha, melhor ou pior. (...) As ruas cruzam-se e recruzam-se, sobem e descem. Em virtude desta disposição inclinada e das montanhas, pode-se ver a multidão de pátios, de ruelas escondidas e de recantos isolados que esta construção, sem plano, fez nascer (...) é impossível imaginar o desordenado amontoado das casas, literalmente empilhadas umas sobre as outras, verdadeiro desafio a qualquer arquitetura racional (ENGELS, 1975, p. 38-61).
\end{abstract}

Por volta da metade do século XIX, dois fatores foram marcantes na definição das cidades e do seu planejamento. A ferrovia, que passou a conectar o centro a novas áreas para habitação mais periféricas, e as leis sanitárias, que visavam controlar as péssimas condições de higiene das cidades à época (HOWARD, 2002). Panerai, et alii (1986), consideram que a organização de transportes suburbanos de grande porte facilitou a propagação do subúrbio, consistindo na origem do progresso de muitas cidades na época.

Ressaltam que a propagação das epidemias alarmou as classes dirigentes, que promoveram a criação de comitês e comissões destinados à investigação das condições de habitação.

Não obstante a acelerada e significativa transformação das cidades inglesas, em 
decorrência da Revolução Industrial, a Inglaterra passou por período conhecido como "A Grande Depressão", iniciado em 1873, que dividiu o país em dois períodos distintos: “de um contínuo e vigoroso crescimento de sua indústria, caracterizando prosperidade e otimismo, para uma época de alterações radicais no processo de crescimento capitalista" (HOWARD, 2002, p. 37).

No final do século XIX, a população urbana inglesa constituía a exorbitante marca de 75\% da população do país (HOWARD, 2002). Em um século (entre 1820 e 1914), a dimensão urbana de Londres passou de cinco para quinze quilômetros. Este crescimento ocorreu, em grande parte, devido à proliferação de "estates", casas muito semelhantes, construídas de modo sistemático, enfileiradas, configurando extensas zonas urbanizadas. A crescente construção de "estates" ocorreu, sobretudo, devido ao alcance de maioria socialista na organização administrativa da cidade (PANERAI et alii, 1986).

No início do século XX, acirraram-se as discussões acerca dos subúrbios de Londres, e o socialismo readquiriu forças (no início do século XIX, atitudes socialistas foram presenciadas, a exemplo daquelas realizadas por Robert Owen, pioneiro do socialismo e do cooperativismo, entretanto, sofreram fim precoce), e o operariado inglês tornou-se mais organizado. Dois pontos de vista conflitavam. Vertente socialista, que defendia a possibilidade de realização de todas as etapas da geração e distribuição de riquezas pela comunidade; e corrente individualista, partidária da execução de tais etapas de modo individual (HOWARD, 2002).

Há, ainda, que se destacar a influencia do movimento "Arts \& Crafts", retratado na Exposição Industrial de Londres, em 1851, no Palácio de Cristal. O movimento demostrava o desencanto pela baixa qualidade estética dos produtos fabris, atribuída à desvalorização do trabalho humano operário, desprovido de participação criadora, na era industrial. Considerava que quando a produção era artesanal, na cidade medieval - de pequeno porte e ligada ao ambiente rural -, quando havia relacionamento produtivo entre mestres e artesãos, as relações de produção eram mais equilibradas. Portanto, os integrantes do movimento "Arts \& Crafts" lutavam pela formação de agrupamentos urbanos de pequeno porte ligados à natureza, em contrapartida às grandes cidades industriais (PANERAI, et alii, 1986). Neste período foram delineadas as pesquisas e estudos realizados por Ebenezer Howard, aos quais se agregou a uma série de grupos de leitura e discussão, como uma oportunidade de adquirir conhecimento acerca das grandes 
questões políticas e econômicas da época. Fishman (1982) salienta que, nestes grupos, o estenógrafo encontrou indivíduos que possuíam preocupações semelhantes às suas, e se iniciou no mundo da classe média radicalista de Londres. Entretanto, Howard expunha postura conciliatória perante as tendências socialista e individualista, considerando que, do socialismo, seria possível aproveitar a concepção de esforço comum e o conceito de vida municipal e, do individualismo, seriam louváveis a preservação do auto-respeito e da autoconfiança (HOWARD, 2002). Conforme Fishman (1982), Howard conferiu ao movimento radical não apenas uma nova meta, mas a estratégia de ação que faltava, construindo novas cidades, criando um novo ambiente - o caminho para a comunidade cooperativa.

\subsection{As Cidades-Jardins de Ebenezer Howard}

Em 1898, Ebenezer Howard, estenógrafo, publicou o livro intitulado "Tomorrow: A Peaceful Path to Real Reform”, que foi revisado e reeditado, em 1902, sob o título "Garden Cities of Tomorrow". Neste livro, o autor propôs o conceito de "Cidade-Jardim", no qual se inseria o entendimento de que o campo constitui lugar privilegiado para a instalação de cidades equilibradas. Objetivando esclarecer as vantagens que considerava existirem em seu conceito, esboçou esquematicamente o que denominou diagrama dos "Três Ímãs", que expõe, em dois dos imãs, as vantagens e desvantagens existentes na cidade e no campo e, no terceiro imã (cidade-campo), busca conciliar as vantagens inerentes à cidade e ao campo, e evitar as deficiências de ambos. O imã cidade-campo representa a essência do assunto a ser desenvolvido por todo o livro.

Embora não tivesse formação em arquitetura ou planejamento urbano (...) Howard se esforçou pacientemente para projetar aquele Terceiro Ímã que chamou de Cidade Jardim, cuja promessa de uma vida melhor afastaria as pessoas dos centros urbanos para uma nova civilização (Tradução das autoras) (FISHMAN, 1982, p. 39).

Fishman (1982) considera que Howard, apesar do seu modo tranquilo e discreto de agir, foi um revolucionário, responsável por originalmente conceber a Cidade-Jardim como um meio de superar o capitalismo, criando uma civilização baseada no cooperativismo. Embora não fosse arquiteto nem urbanista, Howard apresentou a sua 
idealização de cidade através de diagramas que, portanto, não configuravam plantas definitivas.

A Cidade-Jardim, de acordo com as perspectivas howardianas, deveria possuir, em média, trinta mil habitantes dispostos em uma área urbana de mil acres, e dois mil habitantes nos terrenos agrícolas circundantes, ocupando cinco mil acres (HOWARD, 2002). Na cidade, deveria haver, ao mesmo tempo, tranquilos bairros residenciais e instalações para uma ampla gama de atividades comerciais, industriais e culturais. Howard não concebia a Cidade-Jardim enquanto uma "cidade-satélite" especializada ou uma "cidade-dormitório", a serviço de grandes metrópoles. Almejava que as grandes cidades fossem se encolhendo em significância e que a sua população as abandonasse, em busca de uma nova forma de vida, numa sociedade descentralizada (FISHMAN, 1982).

Em outros dois diagramas, elaborados por Howard, foi esquematizada cidade circular dividida em seis setores, havendo um parque central de onde irradiavam seis bulevares arborizados que se estendiam até o perímetro externo, circundado por uma ferrovia que, após envolver a cidade, transformava-se em estrada de penetração no ambiente rural. Do parque central emanavam, ainda, cinco arborizadas avenidas, sendo, a "Grande Avenida", larga e extensa, a proposta de um grande parque (HOWARD, 2002).

Observa-se a preocupação em suprir a cidade com extenso sistema viário, porém, não desvinculado da presença de áreas verdes, fator que, além do intuito de embelezá-la, tornando a paisagem aprazível, demonstrava interesse pela salubridade citadina. Adicionese, Howard não estava alheio à população precariamente instalada nas cidades industriais. Considerava possível alojá-la a baixo custo e alta qualidade ambiental (PANERAI, et alii 1986).

Howard se via como um daqueles sonhadores e pensadores de quintal que emergem da obscuridade com uma grande ideia, corajosa voltada ao mundo "prático"e, finalmente, vê os céticos confusos e a invenção se tornar parte integrante de um mundo melhor. (...)A Cidade-Jardim, esperava ele, seria uma inovação igualmente significativa, revolucionária em si mesma e, como a primeira locomotiva, passível de grandes avanços. Seria um motor de progresso com a capacidade de desbloquear a energia social e mover a sociedade em direção a fins benéficos que nem mesmo seu inventor poderia prever(Tradução das Autoras)(FISHMAN,1982,p.27-28).

Partiu do pressuposto de que, na Cidade-Jardim, o solo urbano e o rural configuravam patrimônio coletivo dos moradores. Deste modo, ninguém poderia ser proprietário de sua casa, comércio, indústria ou terra rural. O solo urbano não constituía 
propriedade do Governo Central, nem deveria ser por ele gerido. Havia submissão somente às leis e tributações. Howard considerava a existência de uma municipalidade, controlada por seus habitantes (HOWARD, 2002). Os habitantes deveriam contribuir mensalmente com cotas de participação, que os habilitavam a usufruir do terreno onde se instalavam. $\mathrm{O}$ pagamento destas cotas era utilizado também para a amortização do empréstimo feito pela comunidade para adquirir a terra agrícola onde se pretendia instalar a Cidade-Jardim, para financiar a construção de infra-estrutura urbana, sistema viário, edifícios públicos e suprir os gastos com a administração da cidade e sua manutenção. O nível de empreendimento e dimensão da municipalidade dependia exclusivamente da disposição dos munícipes a pagar maiores ou menores cotas de participação, o que ressaltava a recorrência ao cooperativismo na Cidade-Jardim (FISHMAN, 1982; HOWARD, 2002).

As propostas de Howard são fundamentalmente econômicas, e sob esta perspectiva analisam o problema da gestão municipal e do financiamento da construção de cidades, apresentando a cidade-jardim como a solução mais econômica e equilibrada para garantir o crescimento de uma grande cidade (Tradução das autoras) (PANERAI, et alii, 1986, p. 51-52).

A proposta elaborada por Howard foi desenvolvida sob a influência de diversos autores, através da conjugação dos aspectos que considerava importantes, de vários projetos defendidos ao longo do tempo, combinando-os. Considerava que o seu projeto constituía uma combinação única de propostas (FISHMAN, 1982), resultante, fundamentalmente, do híbrido de três concepções: (1) as propostas para um movimento migratório organizado de população, de Edward Gibbon Wakefield e do professor Alfred Marshall; (2) o sistema de posse fundiária proposto primeiramente por Thomas Spence e, mais tarde (embora com uma importante modificação), por Herbert Spencer; e (3) a cidade-modelo de James Silk Buckingham (HOWARD, 2002).

De Wakefield e Marshall, absorveu a ideia de formação de colônias balanceadas, compostas por membros de todas as classes, com populações urbana e agrícola equilibradas, formando uma comunidade auto-suficiente. De Thomas Spence, aderiu a consideração das contribuições individuais para pagamento da terra, dos impostos do governo e das obras a serem realizadas. De Herbert Spencer, considerou a proposta de transformar a propriedade privada em propriedade comunitária, sendo todos os homens proprietários e tendo igual liberdade para se converterem em inquilinos da comunidade. De Buckingham, aceitou a hipótese de que a união das atividades agrícolas e industriais é 
vantajosa, ideia defendida também por Wakefield (IDEM). Houve, ainda, a inspiração em outros autores, tais como os americanos Edward Bellamy, indispensável no processo de formação do cooperativismo nos E.U.A., e Henry George, que, apesar de criticado por Howard, o instigou, com ideias publicadas no livro "Progress and Poverty" (FISHMAN, 1982).

Howard abordou a possiblidade de existência de "agrupamento de cidades", que ocorreria quando houvesse o crescimento da Cidade-Jardim. Neste caso, o autor previu a existência de uma rede de cooperação, em que a cidade mais beneficiada partilhava as suas vantagens com as demais, através de uma interligação que possibilitava o uso comum de diversas atividades comerciais, culturais e de lazer, favorecendo a vida individual e coletiva de seus habitantes.

A idéia de cidade bem planejada leva por si mesma à idéia de
agrupamento de urbes cuidadosamente projetadas, de tal modo que cada
habitante de uma com população relativamente pequena pudesse, através
de um sistema bem organizado de ferrovias, canais e estradas de
rodagem, desfrutar de comunicação fácil, rápida e econômica com um
grande aglomerado populacional, fazendo com que as vantagens
oferecidas pela grande cidade por suas formas mais elevadas de vida
social possam estar ao alcance de todos, ao mesmo tempo que cada
cidadão da que haveria de ser a cidade mais formosa do mundo poderia
viver em uma região de ar puro e a pouquíssimos minutos a pé do campo
(HOWARD, 2002, p. 203).

Fishman (1982) destaca e aprecia a existência de um otimismo radical nas ideias de Howard, cuja fé na evolução o teria convencido de que o homem pode e deve superar qualquer ambiente que tenha frustrado a fraternidade humana. Segundo o pensamento de Howard, a transformação do ambiente tornou-se a peça central para a criação de uma nova civilização. Designou ao planejador - responsável pela imaginação e justiça - a tarefa de projetar casas e cidades que fariam da cooperação entre os homens e do contato com a natureza as bases da vida cotidiana.

A primeira concretização da utopia de Howard foi a partir de 1904 com Letchworth, a primeira Cidade-Jardim, implantada a cinquenta e seis quilômetros de Londres, cujo plano de implantação foi executado pelos arquitetos Raymond Unwin e Barry Parker, que, juntamente com Howard, fundaram uma sociedade com participação em ações, responsável por financiar as obras desta primeira cidade-jardim (PANERAI et alli, 1986). 
Anos mais tarde, a partir de 1920, iniciou-se a construção da segunda CidadeJardim, Welwyn, em um terreno situado a quinze quilômetros de Letchworth e a vinte e dois quilômetros de Londres (HOWARD, 2002). A cidade foi prevista para quarenta mil habitantes, com possiblidade de aumento para cinquenta mil, tendo seu plano sido elaborado pelo arquiteto Louis de Soissons. Em Welwyn, do mesmo modo que em Letchworth, as residências dispunham de jardim fronteiriço, sem muros entre si e a rua, passeios com gramas, arbustos e intenso arvoredo, dispostos junto às vias com pouco trânsito de passagem ou em "cul de sac", tendo, no centro da quadra, jardins coletivos, harmonicamente vinculados à natureza (PANERAI, et alii, 1986). A partir da construção destas duas Cidades-Jardins, Ottoni esclarece que Howard acreditava ter provado (HOWARD, 2002, p. 66):

a) que era viável a construção de cidades novas com indústrias, independentemente de paternalismos esclarecidos ou do Estado, conservando o incremento do valor terra para a comunidade, em vez de subúrbios-jardins;

b) que cada família poderia possuir uma casa em meio ao verde, com fácil acesso ao trabalho, ao centro da cidade e ao campo;

c) que se poderia obter muito boa qualidade ambiental, não só nas partes centrais das cidades, mas por todo seu conjunto, mediante cuidados paisagísticos, atravessando toda a cidade e comunicando-se com um cinturão verde definido, evitando-se colocar a área agrícola circundante como uma terra ainda não construída, mas sim como um cinturão verde permanente e integrado à cidade;

d) que era possível a construção, a baixo custo, de casas com boa qualidade, externa e internamente, e que o rigor na escolha dos materiais e no respeito às normas estabelecidas evitava a diferenciação frente e fundos em sua arquitetura, formando um todo homogêneo e contínuo para a cidade.

Howard demonstrou, de modo claro e objetivo, através da proposta de CidadeJardim, que o ideal de viver em habitações saudáveis e rodeadas áreas verdes naturais é factível, podendo ser realizável a baixo custo e de modo socialmente desejável.

Fishman (1982) considera que, não obstante o fato de a proposta de Howard configurar utopia urbana, no processo de elaboração do modelo Cidade-Jardim, houve uma tentativa de considerar os problemas urbanos como um todo. Buscou-se compreender a lógica das cidades do século vinte, a sua estrutura inerente, e sua forma mais eficiente. Tentou-se incidir um olhar que fosse além das distorções impostas por uma ordem social desumana, visando uma cidade baseada na justiça social e na equidade.

\section{Cidades-Jardins no Brasil: Surgimento e Distorções}


A proposta de Cidade-Jardim desenvolvida por Howard se difundiu, no início do século XX, por todo o mundo, inclusive pelo Brasil. Entretanto, via de regra, restringiamse à produção de subúrbios-jardins de qualidade variável, visando apenas a melhoria do ambiente residencial da classe média alta.

No Brasil, o conceito proposto por Howard passou por uma espécie de reducionismo, na medida em que, em lugar de ser implantado com vistas à resolução de problemas sociais, foi, em muitos casos, realizada a utilização do termo "Cidade-Jardim" com fins propagandísticos de loteamentos, ou bairros de luxo.

Em Minas Gerais, o arquiteto Lúcio Costa projetou, em 1934, a vila operária de Monlevade, com a inserção de aspectos semelhantes aos dos subúrbios-jardins norteamericanos, espécie de planejamento que Howard não previu para as suas Cidades-Jardins. Em Belo Horizonte, a expressão "Cidade-Jardim" foi utilizada para auferir status a diversos empreendimentos da época. Em 1950, o arquiteto Sergio Bernardes projetou a "Cidade-Jardim Eldorado", no município de Contagem, sob a influência da cidade-jardim. Concebida para ser um loteamento com conjuntos residenciais auto-suficientes, na "Cidade-Jardim Eldorado", observava-se a influência da proposta de Cidade-Jardim de Howard e dos planos de Unwin para Londres e de Soissons para Welwyn Garden City (ANDRADE, 2000).

Na cidade do Rio de Janeiro, o urbanista francês Alfred Agache propôs, em 1930, através do plano "A Cidade do Rio de Janeiro - Extensão, Remodelação, Embelezamento", duas Cidades-Jardins para as ilhas do Governador e Paquetá. Além disso, em diversos bairros valorizados da cidade, tais como Laranjeiras, Gávea e Jardim Botânico, vários loteamentos foram realizados, livres da instalação de estabelecimentos comerciais e indústrias (HOWARD, 2002). Observa-se que a desvinculação destes loteamentos com áreas industriais configura fator que desvirtua a ideia de Cidade-Jardim de Howard, que previa a instalação de indústrias e comércio, de modo a garantir a auto-suficiência dos seus habitantes.

Na cidade de Goiânia, o plano desenvolvido por Atílio Corrêa Lima, previu a construção, na zona sul da cidade, de ruas curvas, contendo "cul de sac", beneficiadas por extensa vegetação. Com o afastamento de Lima e sua substituição pelo engenheiro 
Aramando de Godoy, adotou-se a concepção norte-americana de subúrbio-jardim (ANDRADE, 2000).

Outro projeto no qual haveria a pretensão de inserir a ideia de Cidade-Jardim foi o plano para Brasília, elaborado por Lúcio Costa, vencedor do concurso realizado em 1957. Entretanto, nesta proposta, existiam tendências que se distanciavam daquelas presenciadas nas Cidades-Jardins howardianas, identificando-se maior proximidade com a noção de "cidade-verde" de Le Corbusier (IDEM).

A cidade brasileira onde ocorreu a implantação mais extensa da proposta de Howard foi São Paulo. Em 1912, a companhia "City of São Paulo Improvements and Freehold Company Ltd", realizou a compra de mil e duzentos hectares de terras que envolviam a cidade, o que constituiu vultoso investimento inglês em São Paulo. Nesta área, o primeiro bairro a ser loteado foi o "Jardim América", planejado por Barry Parker e Raymond Unwin. A pretensão foi desenvolver um loteamento-jardim, estritamente residencial, não auto-suficiente, o que, a princípio, contraria a ideia original de CidadeJardim. O projeto previa lotes com aproximadamente mil quatrocentos e cinquenta metros quadrados, dispostos em ruas sinuosas, com jardins internos às quadras, para uso coletivo dos moradores. Dispunha de dois clubes e da Igreja Nossa Senhora do Brasil. Os jardins, presentes, por todo o bairro, somados à substituição de muros por cercas vivas, mantinham a proposta de verde contínuo (HOWARD, 2002). O alto nível arquitetônico das residências e a beleza do jardim contínuo atribuíram status ao bairro que, ainda hoje, mantém as características inicialmente propostas por Parker e Unwin. Diversos outros loteamentos, em São Paulo, seguiram o padrão implantado no bairro Jardim América, entre os quais, Morumbi, Cidade-Jardim, Ibirapuera, Pacaembu, Alto de Pinheiros, Butantã.

Constata-se, todavia, que os projetos de Cidade-Jardim desenvolvidos no Brasil tendem a ser não auto-suficientes e voltados para parcela elitizada da sociedade. Mantém apenas o caráter de intensa presença de áreas verdes circundantes, o que não constitui fator suficiente para classificá-los enquanto modelos de Cidades-Jardins propriamente ditos. Isto porque Howard propunha, concomitante à existência de ruas arborizadas, parques, praças verdes e cinturão agrícola, o ideal de espaço auto-suficiente e cooperativo, voltado sobretudo às classes operárias, com a previsão de instalação de indústrias e comércio, sem, no entanto, prejudicar a salubridade da região. 


\section{A mercadorização do conceito de Cidades-Jardins: da deturpação do ideal howardiano à elitização e apropriação da natureza nas cidades}

A partir do início do século $\mathrm{XX}$, passou a existir no Brasil tendência ao planejamento de loteamentos residenciais que prezassem pela existência de áreas verdes, em geral, voltados para o público elitizado. Desde então, observa-se muitas vezes que os empreendedores se propõem a construir bairros nos moldes de Cidades-Jardins, concretizando, entretanto, tais pretensões, de modo deturpado ou incoerente com a original ideia difundida por Howard.

Nas últimas décadas, constata-se que vem ocorrendo intensa atuação do mercado imobiliário no sentido de utilizar a natureza nas cidades como objeto rentável, apropriando-se, de forma exploratória, enquanto mercadoria. Castells, ao abordar o processo de "mercadorização" da natureza pelo capitalismo, ressalta que "basta pensar no processo de privatização dos recursos naturais para observar que nada pode escapar ao grande capital; no interior de uma lógica capitalista dominante, tudo, absolutamente tudo, pode tornar-se mercadoria" (1983, p.491).

O marketing imobiliário, em muitos casos, difunde a ideia de que o viver bem na cidade está associado ao convívio próximo à natureza, o que leva ao aumento do valor dos imóveis localizados em setores da cidade onde a riqueza natural é predominante. $\mathrm{O}$ objetivo é atrair consumidores de alto poder aquisitivo, dispostos a pagar exorbitantes valores monetários para desfrutar de suposto convívio saudável junto à natureza.

É evidente que a publicidade insistente e a mídia têm um papel especial na dissimulação da realidade do ambiente construído e na construção da sua representação, destacando os espaços de distinção. É evidente também que a representação ideológica é um instrumento de poder - dar aparência de "natural" e "geral" a um ponto de vista parcial, que nas cidades está associado aos expedientes de valorização imobiliária. A representação da cidade encobre a realidade científica (MARICATO, 2002, p.165).

De acordo com Lefebvre, os promotores de venda apresentam projetos com "ocasião e local privilegiados: lugar de felicidade numa vida quotidiana miraculosa e maravilhosamente transformada" (2011, p.32).

O público consumidor é representado por compradores que se dispõem a pagar os altos valores monetários, para usufruir do que Henrique considera uma natureza congelada, carregada de ideologia, transformada em cartão postal, em fetiche. "Esta natureza artificial, 
produto da ação humana e, de mentira, (...) encontra-se hoje compromissada com uma felicidade capitalista" (2008, p.204).

A falta de veracidade no uso da natureza pelo marketing imobiliário reside, sobretudo, no fato de que se busca acobertar os males da cidade, ofuscando-se a miséria, a violência, a falta de solidariedade e de cidadania (ROCHA, 2003). Transmite-se a ideia de que, morando próximo à natureza, o cidadão livra-se dos tantos problemas inerentes à realidade atual das grandes cidades. Lefebvre considera que todas as condições se reúnem "para que exista uma dominação perfeita, para uma exploração apurada das pessoas, ao mesmo tempo como produtores, como consumidores de produtos, como consumidores de espaço" (2011, p.33). Pretende-se a difusão de um mundo encantado, perfeito, repleto de ilusões, longe do "mal" das cidades. Cria-se uma utopia infantilóide acerca da possibilidade de se viver em lugar de sonhos e plenitude do "bem", a partir da representação glamourizada, reificada e caricaturizada da natureza, que é vista como se numa tela de cinema. A este processo Harvey (2000) conceitua como "Disneyficação da Natureza". O autor considera que a disneyficação configura a ideia de espaço supostamente feliz, harmonioso e sem conflitos, apartado do mundo real; de entretenimento; de história inventada; de cultivo de nostalgia de um passado mítico; do fetiche pela cultura da mercadoria; da reunião de objetos e coisas difusoras da ideia de diversidade e existência multicultural, mesmo que ocorra na forma de compartimentos; de lugar limpo, higienizado e mitologizado, esteticamente perfeito.

Além disso, na atual conjuntura da sociedade de risco ${ }^{1}$, com degradação crescente dos recursos naturais, viver próximo à natureza parece estar associado a realidade privilegiada. Neste sentido, o mercado imobiliário tem agido de modo a adquirir vantagens, vendendo imóveis a altos valores, devido ao "privilégio" de se localizarem em áreas onde há vasta riqueza natural. Constroem-se e se vendem cidades ilusionarias para compradores que tem poder aquisitivo suficiente para se iludir, para crer ver o invisível que o marketing imobiliário torna visível.

Os marketeiros ocupam papel importante na construção da invisibilidade e visibilidade da cidade, separando os legítimos interesses da

\footnotetext{
${ }^{1}$ Sociedade de risco consiste em modelo sociológico, desenvolvido por Ulrich Beck, que descreve o estado em que se encontra a sociedade pós-moderna: diante da organização capitalista dos processos de exploração dos recursos naturais, em que os perigos e os riscos advêm das mais diversas origens, o que dificulta o controle desses problemas por parte dos diversos setores da sociedade, entre os quais, a sociedade civil, as organizações associativas, as instituições públicas ou privadas. Fonte: LEITE, José Rubens Morato; AYALA, Patryck de Araújo. Direito Ambiental na Sociedade de Risco. Rio de Janeiro: Forense Universitária, 2002.
} 
população,(...) dos interesses demagógicos que ocultam propositadamente os males da cidade, (...) através da construção da cidade-vitrine, da cidade-espetáculo, da cidade que ofusca a miséria, a violência, a ausência de solidariedade e a cidadania com seus fogos de artifício, suas festas e seus balangandãs. Esta cidade é constantemente construída e destruída nos outdoors, cartões-postais e cadernos de turismo, pela força da mídia na sociedade, requerendo dos construtores da invisibilidade e visibilidade um permanente diálogo na tentativa de se alcançar uma cidade mais justa, democrática, agradável,pelo resgate da cidadania (ROCHA,2003,p.6667).

Segundo Lefebvre, "as pessoas se representam a si mesmas através daquilo que lhes falta ou que acreditem faltar. Nesta relação, o imaginário tem mais poder”. Para o autor, esta realidade ilusionária, criada pelo marketing imobiliário, configura o "imaginário do habitat", onde está presente o sonho, a saúde, afastados da cidade "má e malsã" (LEFEBVRE, 2011, p.27). Não mais se vende uma moradia ou um imóvel, mas o urbanismo, que passa a ser reconhecido como valor de troca. E tudo isso acontece (surpreendentemente ou não), sob os auspícios do Poder Público.

Esta tendência de apropriação da natureza pelo marketing imobiliário é comumente verificada nos empreendimentos conhecidos enquanto "condomínios fechados", a saber, os condomínios fechados de luxo. A proliferação dos condomínios fechados protegidos e de luxo, para onde as camadas sociais de média e alta renda se dirigem, em busca de segurança e qualidade de vida, tem sido uma tendência dominante na dinâmica das megalópoles brasileiras, desencadeando aumento da auto-segregação dos ricos e isolamento dos pobres (CARVALHO e PEREIRA, 2008).

Nesse contexto, convém ressaltar que a instrumentalização da natureza em prol do mercado, tornando, áreas verdes, acesso aos Parques e às praias exclusivos, por meio de muros, tapumes e caminhos restritos aos moradores de determinados condomínios fechados de luxo, além de se configurar como exemplos de anticidades dentro da urbe, visto que fragmentam o tecido urbano e impedem a circulação livre de pessoas, também se configuram em desrespeito às leis ambientais vigentes, sobretudo no que se refere ao artigo 225 da Constituição Federal de 1988.

A utilização dos equipamentos urbanos voltados à natureza enquanto bens passíveis de apropriação por alguns detentores de poder financeiro fere frontalmente o direito à natureza nas cidades. Conforme promulga a Constituição, "todos têm direito ao meio ambiente ecologicamente equilibrado (...) essencial à sadia qualidade de vida" (art. 
225, caput, CF/88). Negar esse direito é negar, inclusive, uma das facetas do Direito à Cidade.

A reprodução destas incongruências faz perpetuar as disparidades socioeconômicas inerentes a tantas cidades brasileiras. À exemplo de Salvador, as cidades brasileiras apresentam grandes desigualdades sociais também decorrentes de importante segregação socioespacial evidenciada, principalmente, nos grandes centros urbanos, resultando em problemas gravíssimos (ALFONSIN, 2008; CAU/RS, 2017).

\section{Cidades-jardins à moda Soteropolitana: Condomínios Fechados de Luxo em confronto com a legislação urbanística vigente. E o Direito à Cidade?}

A cidade de Salvador, entre os anos de 1940 e 1950, devido, sobretudo, a um processo migratório intenso, sofreu crescimento demográfico e gerou modificação da sua estrutura espacial, em decorrência de fatores como a reestruturação funcional do centro da cidade. Até os anos quarenta, este setor da cidade abrigava a população de alta renda; a partir desse período, passou a ser ocupada pela população de baixa renda. Este processo ensejou a expansão para a periferia urbana (CARVALHO e PEREIRA, 2008). Nos anos de 1980 iniciou-se o delinear de um novo centro urbano na cidade, com a construção da Avenida Paralela, do Centro Administrativo da Bahia, da nova Estação Rodoviária e do Shopping Iguatemi, impulsionado por grandes empreendimentos públicos e privados realizados na década anterior. Essa mudança de localização do centro urbano direcionou a expansão urbana no sentido da orla norte e contribuiu para o gradativo esvaziamento do centro tradicional, localizado na área antiga da cidade (SCHEINOWITZ,1998). Neste mesmo período, a instalação do Polo Petroquímico de Camaçari, a construção da Estrada do Coco, que tornava o acesso entre Salvador e Lauro de Freitas (cidade que se conurba com a Capital) facilitado, gerou ampliação dos investimentos imobiliários no setor, que passou a abrigar empreendimentos mais qualificados. Um exemplo é o "Vilas do Atlântico", projetado como novo conceito de moradia, que associava uma vida saudável integrada à natureza, idealizando comunidade homogênea que viveria longe da criminalidade e de outros males urbanos. A partir de então, outros loteamentos e condomínios fechados de alto padrão passaram a se instalar na região, atraindo segmentos de média e alta renda de Salvador (CARVALHO e PEREIRA, 2008).

Até antes da atual pandemia de COVID-19, Salvador apresentava-se enquanto uma metrópole nacional, detentora de grande potencial turístico, devido, sobretudo, ao fato 
de dispor de diversificada riqueza natural. Vinha incrementando crescentemente a metropolização turística, destacando-se no cenário nacional e mundial. Porém, com quase 3 milhões de habitantes (IBGE, 2010), terceira capital do Brasil, dispõe de aproximadamente apenas $14 \%$ de áreas aptas a novas ocupações habitacionais - o que demonstra a existência de déficit habitacional -, além de estar sofrendo gradativo aumento nos seus índices de violência. Estes dados demonstram que a cidade apresenta dois vetores de estruturação do espaço urbano: favelas (ocupações espontâneas), e condomínios fechados.Ambos se destacam por explicitar as tensões sociais que caracterizam a ocupação desigual do espaço da cidade e as contradições entre a dimensão do público e do privado (IVO, 2012).

Na Bahia, de acordo com o IBGE (2010), o déficit total de unidades habitacionais está em torno de 510.577, das quais 141.000 na Região Metropolitana de Salvador. A pressão exercida por esse déficit é responsável pelo encarecimento do preço do solo urbanizado, fazendo com que a população pobre e os agentes públicos (responsáveis por suprir esse déficit) disputem o mesmo espaço com agentes do mercado imobiliário. Com o intuito de garantir o acesso à terra urbanizada e bem localizada para a produção de habitação social, o Estatuto da Cidade, referendando a Constituição Federal, reforçou a tese de que a terra precisa cumprir uma função social (BALTRUSIS, MOURAD, 2014, p. 267).

Os condomínios fechados, sobretudo os de luxo, negam a realidade cotidiana das cidades, que consiste na interação dos bairros, na diversidade cultural, no encontro de cidadãos nas ruas, praças, comércio, anulando a experiência da vida pública, múltipla e diversa (HENRIQUE, 2009). Concomitantemente, negam os preceitos idealizados por Howard, consubstanciados, sobretudo, no princípio da cooperação entre os indivíduos.

Em contexto antagônico àquele proposto por Howard às Cidades-Jardins, os Condomínios de luxo são implantados em setores onde interesses econômicos, necessidades sociais e ecológicas disputam o espaço de maneiras incompatíveis (SCHEINOWITZ, 1998). Tais empreendimentos, situados preponderantemente na Costa Atlântica, propiciam impactos ambientais vultosos, geram impactos de vizinhança, tanto aos cidadãos que dependem da região litorânea para subsistência, quanto à sociedade como um todo, que tem direito ao meio ambiente ecologicamente equilibrado. Além disso, dificultam o cumprimento da Função Social do solo urbano nas regiões onde se instalam.

Nos Condomínios Fechados de luxo, ambiciona-se auto-segregação, privilégios à classe econômica detentora de poder aquisitivo suficiente para habitá-los, exploração da 
natureza, exclusivismo, entre outros fatores que distam, em muito, dos ideais de troca, e fluxo presentes na ideia original de Cidade-Jardim.

Howard pretendia a criação de ambiente citadino que fosse voltado a uma vida satisfatória também para a população mais carente economicamente (a classe operária), onde se ressaltasse o cooperativismo e a interação com a natureza, numa cidade harmônica e equilibrada, onde a justiça social fosse imprescindível. Tais aspectos são consonantes com o Direito à Cidade e à Função Social do uso do solo urbano, presentes na legislação urbana brasileira atual, a saber, Constituição Federal de 1988 (art. 182) e Estatuto da Cidade (art. $2^{\text {o; }}$ art. 39, Lei n ${ }^{\circ} 10.257 / 01$ ).

É possível afirmar que a cidade só cumpre sua Função Social quando atende aos principais direitos da população de forma justa, igualitária e democrática, de forma sustentável ambiental e socioeconomicamente, em favor de todos que a habitam. A Função Social refere-se ao Direito à Cidade, à universalização do acesso à moradia e à terra urbana (ALFONSIN, 2008). A cidade também cumpre sua Função Social quando a melhoria da qualidade de vida da população é ampliada e o espaço urbano passa a servir em favor do conjunto da população de forma igualitária, com acesso de todos aos bens e serviços, ao transporte e mobilidade urbana, saneamento ambiental, equipamentos públicos de saúde, educação, cultura e lazer.

\section{Considerações finais}

O contexto em que surgiu e se desenvolveu a ideia de Howard era de miséria e pobreza da maior parte da população, insalubridade nas novas cidades industriais. Eximindo-se do reducionismo de comparações, pode-se afirmar que o contexto em que surgiram os condomínios fechados no Brasil, é, igualmente, de miséria e desigualdades sociais. Entretanto, diferentemente do projeto de Howard, que visava a melhoria da cidade como um todo, os condomínios fechados são exclusivistas e burgueses, demonstrando descaso com a realidade circundante e descumprindo o compromisso constitucional com a Função Social das cidades, ao ferir o disposto no artigo $182, \S 2^{\circ}$, da Constituição Federal de 1988 e no Estatuto da Cidade.

Observa-se clara desconstrução das propostas elaboradas por Ebenezer Howard. Quando previu um agrupamento de cidades, demonstrou a existência de intercomunicação, de colaboração, e a fruição das benesses da cidade mais favorecida pelos habitantes de 
todas as demais, de forma cooperativista. Nos atuais condomínios fechados de luxo, o que se propõe é, via de regra, a fragmentação do tecido urbano, a construção de uma área habitacional repleta de vantagens, sobretudo ligadas ao consumo, que são exclusivas aos moradores do local. A intenção é oposta às Cidades-Jardim: não há a ideia de partilhar os benefícios destas "cidades favorecidas" com os habitantes da "cidade desfavorecida" (ou melhor, da cidade propriamente dita); a exclusividade, a ideia do "ter algo a mais e melhor, que outro(s) não pode(m) ter”, é a que nutre a proliferação dos condomínios fechados de luxo no Brasil, em particular, em Salvador.

Adicione-se, o marketing que envolve a natureza em empreendimentos de luxo, tem se revertido em altos lucros para o mercado imobiliário, devido à ampliação da procura, pelo mercado consumidor, de habitações que disponham, entre outros fatores, de áreas verdes em seu entorno, convertendo-se o uso do bem ambiental, difuso e indivisível, em favor do mercado e em desfavor ao Direito à Cidade. A utopia de Howard não tinha fins marqueteiros e excludentes; pelo contrário, visava a agregação, através da ação cooperativa; a melhoria da saúde dos habitantes, a partir dos esforços em construir uma cidade repleta de áreas verdes; a fruição desses benefícios por todos os habitantes da cidade; não havia a intenção de realizar apropriação da natureza para uso exclusivo de poucos.

Diante destes fatos, e de outros mais que poderiam ser elencados, observa-se a existência de antítese e incongruência entre a ideia defendida por Ebenezer Howard, com claros objetivos de cumprimento da Função Social da cidade, e as propostas estabelecidas pelos empreendedores dos atuais condomínios fechados de luxo: princípio da cooperação versus princípio do exclusivismo; pretensão de melhorar as precárias condições de habitação da classe operária versus nutrir os caprichos uma classe abastada economicamente; cidade de todos versus espaço para poucos....

Importante observar que a oferta de "luxo", "natureza" e, consequentemente, "felicidade", direciona-se apenas à "nobreza" da sociedade. Verifica-se, a preponderância da anteposição e sobreposição dos interesses da parcela populacional mais abastada economicamente, em relação às camadas sociais de menor poder aquisitivo, características não encontradas na proposta de Howard, que almeja uma vida satisfatória também para as classes mais carentes, numa cidade harmônica, cooperativa e equilibrada, onde a justiça social seja imprescindível. 
Estes fatores ensejam questionar: de que modo se faria possível partilhar das hipóteses que afirmam ser, muitos dos atuais condomínios fechados de luxo, a recriação da ideia de Cidade-Jardim proposta por Ebenezer Howard? Parece impossível reconhecer esta possibilidade. Lamentável é perceber que não há compromisso com a verdade por parte dos empreendedores de tais condomínios. O utilizar de palavreado expressivo, elegante, como o de um "condomínio-jardim", ou um "condomínio-clube", que agregue valor ao empreendimento e represente a preferência do público consumidor, parece ser o bastante, para o marketing imobiliário. Afinal, quantos dos propensos compradores terão a curiosidade ou o interesse em saber se aquele suntuoso empreendimento, do qual pretendem fazer parte, obedece aos reais ditames da cidade-jardim original ou está em acordo com a legislação vigente?

Embora o urbanismo e o desenvolvimento urbano que cumpra suas funções democráticas e respeite os interesses comuns da sociedade não apareçam com frequência em debates cotidianos, estes temas precisam ser reconhecidos enquanto essenciais para a conscientização da população e para o desenvolvimento de cidades menos desiguais.

Entre outras medidas, talvez fosse oportuno que parcela da população esclarecida sobre o tema se manifestasse em repúdio a este explícito ato de apropriação indevida de um conceito elaborado de forma árdua e séria, inclusive apropriando-se do bem comum indevidamente, ferindo as leis urbanas e a Constituição Brasileira, que vem tendo seus objetivos desrespeitosamente deturpados.

\section{Referências}

ALFONSIN, Betânia de Moraes. A Política Urbana em disputa: desafios para a efetividade de novos instrumentos em uma perspectiva analítica de Direito Urbanístico Comparado (Brasil, Colômbia e Espanha). Tese (Doutorado em Planejamento Urbano e Regional). Programa de Pós-Graduação em Planejamento Urbano e Regional, Universidade Federal do Rio de Janeiro, Rio de Janeiro, 2008.

ANDRADE, Carlos Roberto Monteiro. Ressonâncias do tipo cidade-jardim no urbanismo de cidades novas no brasil. Revista do Seminário de História da cidade e do Urbanismo, n. 1, v. 6, p. 1-15, 2000. Disponível em: http://www.anpur.org.br/revista/rbeur/index.php/shcu/article/view/738/713. Acesso em 15 mai. 2020.

BALTRUSIS, Nelson; MOURAD, Laila Nazem. Política Habitacional e Locação Social em Salvador. Caderno CRH: Dossiê. Maio/Ago. 2014, Salvador, v. 27, n. 71, p. 267-284. 
Disponível em: https://www.scielo.br/pdf/ccrh/v27n71/a04v27n71.pdf. Acesso em 10 abr. 2021.

BRASIL. Constituição da República Federativa do Brasil de 1988. Disponível em: http://www.planalto.gov.br/ccivil_03/constituicao/constituicao.htm. Acesso em: 10 abr. 2021.

Instituto Brasileiro de Geografia e Estatística - IBGE. Censos Demográficos. Disponível em: http://www.ibge.gov.br/home/estatistica/populacao/default_censo_2000.shtm. Acesso em: 10 abr. 2021.

Instituto Brasileiro de Geografia Estatística - IBGE. Censo Demográfico 2010 - Resultados Preliminares da Amostra. Disponível em: http://www.ibge.gov.br/home/estatistica/populacao/censo2010/resultados_preliminares_am ostra/notas_resultados_preliminares_amostra.pdf. Acesso em: 14 abr. 2021

Lei no 10.257, de 10 de julho de 2001. Dispõe sobre o Estatuto das Cidades e dá outras providências. Disponível em: http://www.planalto.gov.br/ccivil_03/leis/leis_2001/110257.htm. Acesso em: 26 mar. 2021.

CARVALHO, Inaiá Maria Moreira de; PEREIRA, Gilberto Corso. As "cidades" de Salvador. In: Inaiá Maria Moreira de Carvalho; Gilberto Corso Pereira (orgs.). Como anda Salvador e sua região metropolitana. Salvador: Edufba, p. 81 - 107, 2008.

CASTELLS, Manuel. A questão urbana. Tradução: Arlene Caetano. Rio de Janeiro: Paz e Terra, 1983.

CONSELHO DE ARQUITETURA E URBANISMO DO RIO GRANDE DO SUL CAU/RS. Função social da cidade: por que todos deveriam saber o que é isso?. Porto Alegre, 2017. Disponível em: https://www.caurs.gov.br/funcao-social-da-cidade-por-quetodos-deveriam-saber-o-que-e/. Acesso em: 10 abr. 2021.

ENGELS, Friedrich. A situação da classe trabalhadora na Inglaterra. Lisboa: Presença, 1975.

FISHMAN, Robert. Urban utopias in the twentieth century: Ebenezer Howard, Frank Lloyd Wright, Le Corbusier. Cambridge: MIT Press, 1982.

HARVEY, David. Espaços de esperança. São Paulo: Loyola, 2000.

HENRIQUE, Wendel. O Direito à Natureza na Cidade. Salvador: Edufba, 2009. Representações da natureza na cidade. In: Angelo Serpa (org.). Espaços

Culturais: vivências, imaginações e representações. Salvador: Edufba, p. 201-223, 2008. 
HOWARD, Ebenezer. Cidades-Jardins de amanhã. Tradução: Marco Aurélio Lagonegro. 2. ed. São Paulo: Hucitec, 2002.

IVO, Any Brito Leal. Jardins do Éden: Salvador, uma cidade global-dual. Caderno CRH. Salvador, n. 64, p. 131-146, 2012.

LEFEBVRE, Henri. O Direito à Cidade. Tradução: Rubens Eduardo Frias. 5.ed. São Paulo: Centauro, 2011.

MARICATO, Ermínia. As idéias fora do lugar e o lugar fora das idéias: Planejamento urbano no Brasil. In: ARANTES, Otília Beatriz Fiori; VAINER, Carlos B.; MARICATO, Ermínia. A cidade do pensamento único: desmanchando consensos. 3. ed. Petrópolis: Vozes, p. 121-192, 2002.

PANERAI, Philippe R.; CASTEX, Jean; DEPAULE, Jean-Charles. Formas urbanas: de la manzana al bloque. Tradução: Santiago Castán. Santiago de Chile: Gustavo Gili, 1986.

ROCHA, Luiz Carlos. Políticas públicas de lazer no subúrbio ferroviário:

(in)visibilidade na dinâmica da cidade de Salvador.Dissertação (Mestrado em Educação) PPGEC, UNEB, Salvador, 2003.Disponível

em:http://www.ppgeduc.com/dissertacoes/turma_1/2001_13_luiz_carlos_rocha.pdf. Acesso em:14 set. 2020 .

SCHEINOWITZ, A. S. O macroplanejamento da aglomeração de Salvador. Salvador: Secretaria da Cultura e do Turismo - EGBA, 1998. 